\title{
The Effect of Problem Based Learning Model with Crossword Puzzles and Motivation Against Digestive System Learning Outcomes of Students
}

\author{
Rodiah Nasution \\ Postgraduate Student of Basic \\ Education Universitas Negeri Medan, \\ Medan, Indonesia \\ diahn4sty@gmail.com
}

\author{
Ramlan Silaban \\ Lecture of Universitas Negeri Medan, \\ Medan Indonesia
}

\author{
Fauziyah Harahap \\ Lecture of Universitas Negeri Medan, \\ Medan Indonesia
}

\begin{abstract}
The problem based learning model with crosswords provides more interesting lessons and exciting to take part in learning for students. Interesting and exciting learning can improve student learning outcomes of the digestive system. there was a requirement of creative and interactive educational method to reinforce the learning objectives of students towards their learning outcomes enhancement. Problem-based learning models with crosswords provide opportunities for students to find solutions to problems that are given more interesting, crosswords that are developed with interesting drawings so students are more motivated to learn. So the aim of the study is to find out the student learning outcomes of problem based learning models with crosswords that are higher than direct learning models of learning; the learning outcomes of the digestive system of students who have high motivation are better than students who have low motivation; the interaction between learning models and motivational learning in influencing learning outcomes.
\end{abstract}

Keywords; Problem Based Learning,Direct Intruction, Motivation, Learning Outcomes

\section{INTRODUCTION}

Education should be able to produce human resources who have the full ability to be able to face various challenges in life. Therefore, changes or educational development is that it should happen in line with the changing culture of life. Education is one of the manifestations of human culture that is dynamic and full development. Students learn better and retain more when they are directly involved in their learning, not just sitting back. It is very necessary to take the feedback from learners that what they have learnt and whether they can talk about what they have learnt, whether they can apply their knowledge in their daily activity

Therefore, changes or educational development is that it should happen in line with the changing culture of life. Changes in the sense of improving education at all levels should continue to be done in anticipation of future interest [7]. The student-centered active learning process within which teacher is merely a guide is the focal point of contemporary education systems. [1]

Education is not only preparing the future, but also how to create the future [5]. Education must be able to form students who have good communication skills and master information technology in the face of globalization. Students must be given capital to have motivation to learn, work together, and be able to solve problems.

Science education at the primary level aims to develop students' thinking ability. Elementary school is the most basic level of formal education given to children. The learning process that is carried out in a formal educational environment is nothing but direct changes in student behavior systematically both in cognitive, affective, and psychomotor aspects.

Good education will be obtained from teachers who are able to bring students to actively participate in the learning process. The teacher must be a master many learning models, media and provide motivation to students to be able to apply the knowledge provided by the teacher in their daily lives.

Problem-based learning model is learning that is characterized by students working together with one another. Collaborating provides ongoing motivation to engage in complex tasks and expand opportunities to share inquiry and dialogue to develop social skills and thinking skills that can influence student motivation [6]. The core of PBL is the presenting the authentic and meaningful problem situation to students that can be the basis of the investigation as in [2]

Media crossword or abbreviated TTS is a game in which students must fill empty spaces with letters that form a word based on the instructions given. Doing crossword puzzles is a fun activity. The crossword puzzle is a kind of word game which can help students to extend their vocabulary knowledge. In exam point of view it plays an important role for solving multiple choice type questions. Thus it can be useful for students to definitions, spelling, and pairing key concepts. The Crossword puzzle is a kind of word game. In crossword puzzle, the blank squares are arranged with number assigned to some of square. The student has to accurately fill in all the blank squares with letters those form words.

The problem based learning model with crossword puzzles can improve writing, reading, and critical thinking activities to solve the given problem. 


\section{LITERATURE REVIEW}

\section{A. Problem Based Learning (PBL)}

Problem-based learning is one of learning that can improve student learning outcomes because PBL is learning that makes students active in learning and help students develop their thinking. PBL is one of learning models designed primarily to help students develop their thinking, problem solving and intellectual abilities, learn the roles of adults by experiencing them through simulated real situations, and become independent and autonomous learners [2]. The essence of PBL model is learning based on problems that require authentic and real investigation as in [3]. Characteristics of PBL are 1) Asking questions or problems, creating questions related to the problem and enabling the emergence of various solutions to solve the problem. 2) Focusing on interdisciplinary linkages, students review the issues from different subjects. 3) Authentic inquiry, students must analyze, establish problems, develop hypotheses and make predictions, collect and analyze information, carry out experiments and draw conclusions. 4) Produce products and publish, demanding learners to produce certain products in form of real work or demonstrations that represent the solution of problems they find. 5) Collaboration, students work together, most commonly forming pairs in small groups. Work together to motivate continuously in more complex assignments and improve the development of social skills [3].

Learning theory that is in line with the PBL model is social constructivism theory from Vigotsky and learning theory from Bruner. In this study PBL with crossword puzzles adapted to the digestive system material. The digestive system image is adjusted to the empty boxes in the crossword puzzle.

\section{B. Crossword Puzzles}

The crossword puzzle is an activity to fill empty boxes which is carried out either downward or horizontally. Using games during teaching is a fun method of including students from diverse cultures and speaking different languages which is applicable during this. In this study use crossword puzzles were constructed using the eclipseword.com, crossword maker website. The crossword puzzle given presents a number of questions, words or phrases as the key to filling in a series of empty boxes that are designed in such a way.

The use of crosswords in classroom learning can improve student vocabulary which leads to students' language abilities. Language is one of the individual abilities that is very important in his life. Language ability is a person's ability to express their thoughts in the form of words and sentence expressions. This is expected to help improve student learning outcomes

The created crossword puzzles have been developed using images and adjusted to arrow directionsbut in making this crossword puzzle is made with images that are in accordance with the digestive system in Figure 1.1. below.

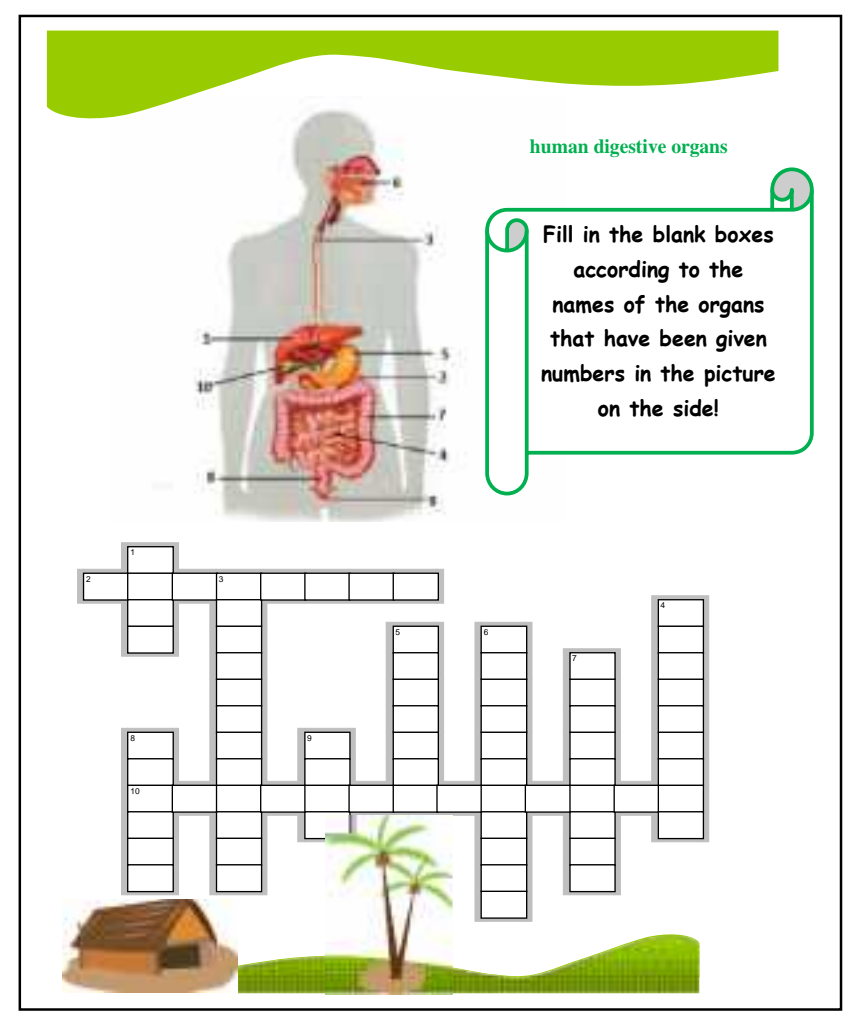

Fig. 1. Crossword puzzles with image

\section{Direct Instruction}

Direct Instruction or direct learning is a learning model where the activities are focused on academic activities. So that in the implementation of learning activities the teacher exerts strict control over the progress of student learning, the utilization of time and a tightly controlled classroom climate as well. The provision of directives and controls is strictly in developing this direct learning model especially when the teacher explains about the learning tasks, explain the subject matter.

This direct learning refers to a model that is a direct explanation from the teacher about new concepts or skills that students will have after learning is done. This explanation is then continued by asking students to test their understanding by practicing under the guidance of the teacher (controlled practice), and encouraging them to continue the practice under the guidance of the teacher (guided practice) so that the expected skills are truly possessed by students [4].

The Direct Instruction learning model has five steps that are interconnected with one another. In conducting this research the phases in the Direct Instruction learning model have five phases, namely: starting from 1) Orientation, 2) Presentation, 3) Guiding Training (structured training), 4) Checking Understanding and Provide Feedback, up to 5) Provide Opportunities for Advanced Training and Implementation [4]. 


\section{METHOD}

\section{A. Research Procedure}

The population of this study were all students of class V public elementary school 114364 Sabungan, which consists of two classes, namely grade five-A, and grade five-B, amounting to 55 people. The sample in this research was grade five-A, and grade five-B. Sampling technique in this research used Total Sampling.Class Va amounts 28 students treated problem based learning model with crossword puzzles (experimental group) and class $\mathrm{Vb}$ amounts 27 students treated direct instruction learning model (control group). Research procedure can be seen below.

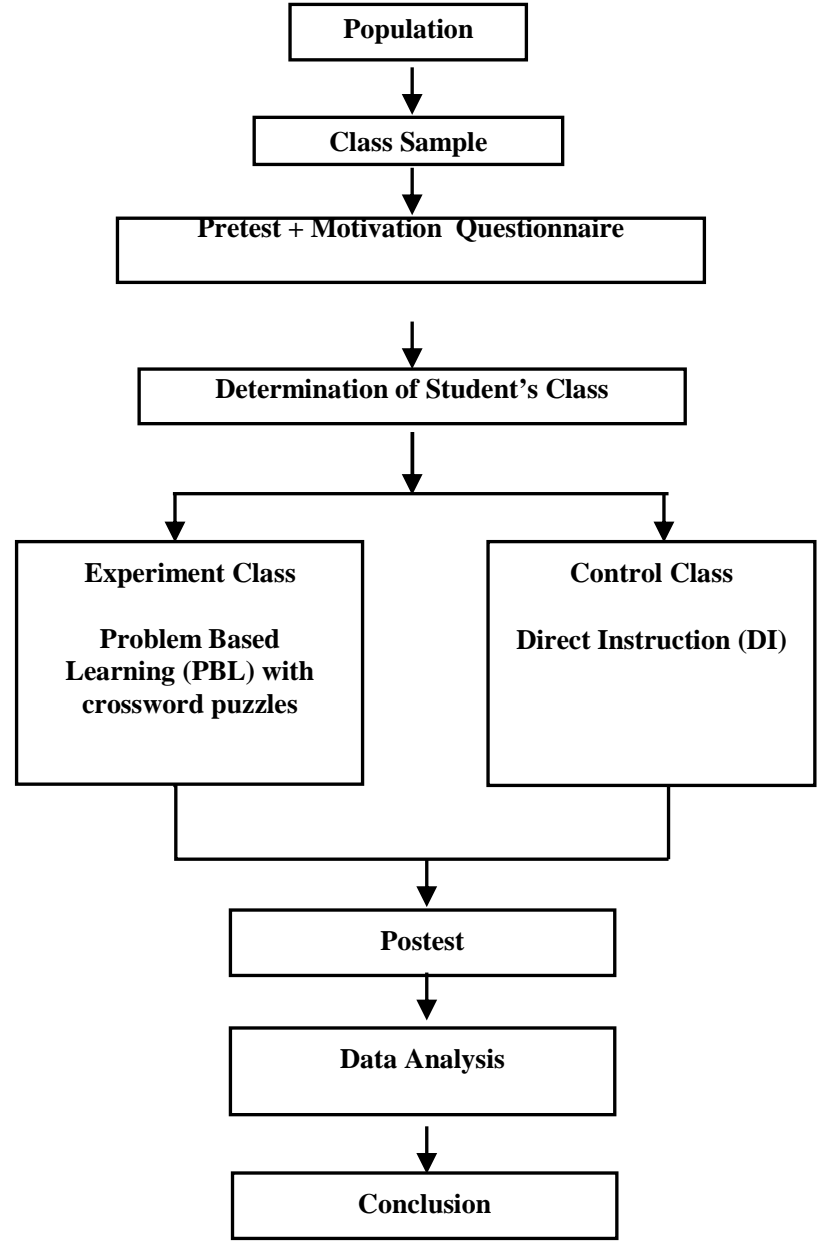

Fig.2. Research procedure

\section{B. Research Design}

The independent variable in this research was problem based learning with crossword puzzle and direc istruction model. The moderator variable used was the motivation in learning which was distinguished between high motivation and low motivation. While the dependent variable is science learning outcomes of student. The instruments were multiple choice tests and learning motivation questionnaire.

The hypothesis of this research was there was problem based learning model with crossword puzzle against science learning outcomes, there was effect of motivation against science learning outcomes, there was an interaction between learning model and motivation against science learning outcomes. Hypothesis tested of this research was conducted by used two-way Variance Analysis (ANAVA) at significance level $\alpha=0.05$ used univariate General Linear Model (GLM) test with SPSS version 25.0 for windows. This study used factorial $2 \times 2$ design with two path ANAVA technique as in the table below.

TABLE. 1. RESEARCH DESIGN

\begin{tabular}{|c|c|c|}
\hline \multirow{2}{*}{$\begin{array}{c}\text { Motoivation in } \\
\text { Learning }\end{array}$} & $\begin{array}{c}|c| \\
\text { LBL with crossword } \\
\text { puzzle } \\
(1)\end{array}$ & $\begin{array}{c}\text { Direct Instruction } \\
\text { (2) }\end{array}$ \\
\hline high(1) & $\mathrm{A1B} 1$ & $\mathrm{A2B} 2$ \\
\hline low (2) & $\mathrm{A1B} 2$ & $\mathrm{A2B} 2$ \\
\hline Average & $\mu \mathrm{A} 1$ & $\mu \mathrm{A} 2$ \\
\hline
\end{tabular}

Information :

A1B1 : Science learning outcomes of students was taught with problem based learning model with crossword puzzles for students who had high motivation.

A1B2 : Science learning outcomes of students was taught with problem based learning model with crossword puzzles for students who had low motivation.

A2B1 : Science learning outcomes of students was taught with direct instruction learning model for students who had high motivation.

A2B2 : Science learning outcomes of students was taught with direct instruction learning model for students who had low motivation.

$\mu \mathrm{A} 1 \quad$ : Mean of student in class PBL with crossword puzzles

$\mu \mathrm{A} 2 \quad$ : Mean of student in class direct instruction

\section{RESULT AND DISCUSSION}

The results obtained in this study include learning scores and questionnaires of students' motivation in learning in the experimental class taught by problem based learning with crossword puzzle and in control class with direct instruction model.

\section{A. Data of Learning Outcomes}

After data is collected it can be seen that the average student learning outcomes in the experimental class have differences. From the mean data of the students postes in experiment class (problem based learning model with crossword puzzles) with control class (direct instruction learning model) showed that there were data of student learning result that was taught with problem based learning model with crossword puzzle was higher than the mean science learning outcomes of student which was taught by direct instruction learning model. 
TABLE 2. PRETEST AND POST-TEST STUDENT LEARNING RESULTS

\begin{tabular}{|c|c|c|c|}
\hline Class & N & $\begin{array}{c}\text { Average } \\
\text { (pretest) }\end{array}$ & $\begin{array}{c}\text { Average } \\
\text { (postest) }\end{array}$ \\
\hline Experiment & 28 & 46,89 & 85,29 \\
\hline Control & 27 & 48,19 & 76,74 \\
\hline
\end{tabular}

Terms of data analysis with parametric statistics was assumption test or prerequisite. In order for later data of research result can be analyzed with parametrik statistic, so need to do normality test and homogeneity test.

\section{B. Test Normality and Homogenity}

Based on the normality of pretest, significant value in Kolmogorov-Smirnov was greater than 0.05 in the experimental and control classes. This result indicated that data in both classes was normal. Then the homogeneity of pretest data showed significant value g reater than 0.05 , so the two classes was homogeneouus. Test normality can be seen in Table below.

\section{TABLE. 3 NORMALITY PRETEST DATA}

\begin{tabular}{|c|c|r|r|r|}
\hline \multicolumn{4}{|c|}{ Tests of Normality } \\
\hline \multirow{3}{*}{$\begin{array}{c}\text { Learning } \\
\text { Outcomes }\end{array}$} & Model Pembelajaran & \multicolumn{3}{|c|}{ Kolmogorov-Smirnov } \\
\cline { 2 - 5 } & $\begin{array}{c}\text { SBL with crossword } \\
\text { puzzles }\end{array}$ & 0,122 & 28 & $0,200^{*}$ \\
\cline { 2 - 5 } & Direct Instruction & 0,153 & 27 & 0,103 \\
\hline
\end{tabular}

\section{Two Path ANAVA Test Result}

After the data collected and analyzed statistics, then performed hypothesis tested. This hypothesis test used twotrack ANAVA test which calculated by SPSS 25 for windows. From the test data obtained learning results, calculated the average of each group and then compiled as two-lane ANAVA. The average learning outcomes and motivation against can be seen in Table 4 .

TABLE.4. ANAVA 2 X 2

\begin{tabular}{ccc}
\hline $\begin{array}{c}\text { Motoivation in } \\
\text { Learning }\end{array}$ & \multicolumn{2}{c}{ Learning Model } \\
\cline { 2 - 3 } & $\begin{array}{c}\text { PBL with crossword } \\
\text { puzzles }(1)\end{array}$ & $\begin{array}{c}\text { Direct Instruction } \\
(2)\end{array}$ \\
\hline high(1) & $\mathbf{9 3 , 4 1}$ & $\mathbf{7 7 , 9 4}$ \\
\hline low (2) & $\mathbf{7 2 , 7 3}$ & $\mathbf{7 4 , 3 3}$ \\
\hline Average & $\mathbf{8 5 , 2 9}$ & $\mathbf{7 6 , 7 4}$
\end{tabular}

To see the difference of motivation and student achievement to the learning given, two way Anova test is used by selecting General Linear Model (GLM) univariate on SPSS 25. This test also aimed to see how the influenced of motivation on student achievement, whether students with high motivation have high learning outcomes or vice versa, and whether there was interaction between learning model and motivation in influenced student achievement.
TABLE.5. TWO PATH ANAVA TEST RESULT

\begin{tabular}{|c|c|c|c|c|c|}
\hline Source & $\begin{array}{c}\text { Type III } \\
\text { Sum of } \\
\text { Squares }\end{array}$ & $\mathbf{d F}$ & $\begin{array}{c}\text { Mean } \\
\text { Square }\end{array}$ & F & Sig. \\
\hline $\begin{array}{c}\text { Learning } \\
\text { Model }\end{array}$ & 607,253 & 1 & 607,253 & 22,487 & 0,000 \\
\hline Motivation & 1865,606 & 1 & 1865,606 & 69,084 & 0,000 \\
\hline $\begin{array}{c}\text { Learning } \\
\text { Model* } \\
\text { Motivation }\end{array}$ & 921,305 & 1 & 921,305 & 34,116 & 0,000 \\
\hline Total & & 55 & & & \\
\hline
\end{tabular}

Based on the data division of high motivation groups and low motivation, then the data of student achievement was grouped accorded to the motivation data. Grouping was done based on the ideal score of motivation of all students. The purpose of grouped were to see student achievement that have high motivation and low motivation.

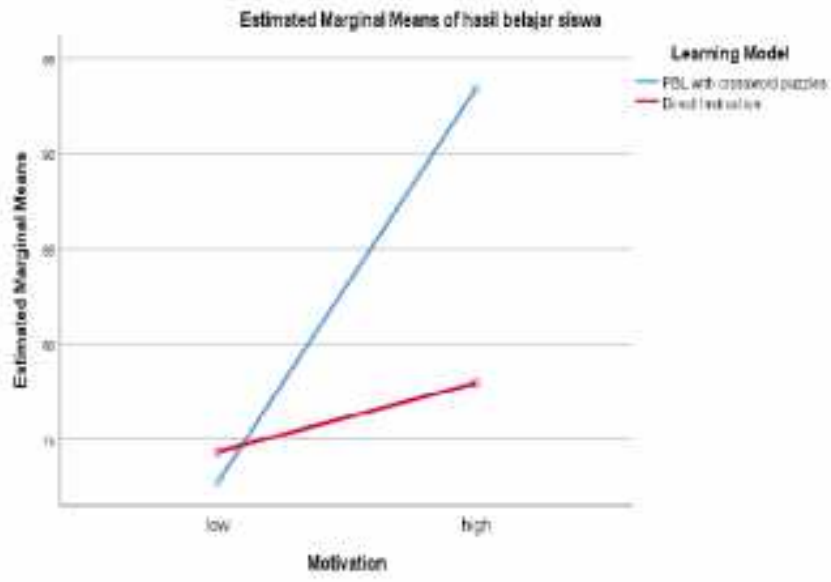

Fig. 2. Interaction chart between problem based learning model with crossword puzzles and DI model with motivation

\section{Hypothesis Test}

The data in above, was used to test the hypotheses proposed in this study. The following was a description of the results of the hypothesis test.

\section{First Hypothesis}

The significance value of learning model was $0,000<$ 0,05 (rejected $\mathrm{H}_{0}$ or received $\mathrm{H}_{\mathrm{a}}$ in the level of $5 \%$ alpha). This showed that there was an effect of learning models. Based on Table 1, postest average of natural science learning outcomes students in problem based learning model with crossword puzzles $(85,29)$ was higher than postest average of direct instruction model $(76,74)$ of natural science.

\section{Second Hypothesis}

The significance value of motivation was $0,000<0,05$ (rejected $\mathrm{H}_{0}$ or received $\mathrm{H}_{\mathrm{a}}$ in the level of $5 \%$ alpha). This showed that there was an effect of motivation. Based on Table 2, natural science learning outcomes of students who had high motivation $(85,46)$ was better than students who had low motivation $(73,45)$. 


\section{Third Hypothesis}

Based on Table 3 and Fig. 2, significance learning model of students motivation in learning was $0.000<0.05$ (reject $\mathrm{H}_{0}$ or receive $\mathrm{H}_{\mathrm{a}}$ in the level of alpha 5\%). This showed that there was an interaction between learning models and motivation influenced natural science learning outcomes of students.

\section{CONCLUSION}

Based on the research that has been done, it can be concluded that improving student learning outcomes with learning Problem Based Learning (PBL) is higher than the average increase in learning outcomes of students taught by direct instruction learning models and evident through the calculation of average student achievement who have high motivation was better than student achievement who have low motivation.

\section{REFERENCES}

[1] Akinoglu, O \& Tandongan, F.O. 2010. "The Effect of Problem-based ActiveLearning in Science Education on Student's Academic Achievment, attitude \& Concept Learning. Eurasia Journal of Mathematics, Science \&Technology Education " P.3 (1) : 71-81

[2] R.I. Arends, Learning To Teach, 7th ed., Yogyakarta, Pustaka Belajar, 2013.

[3] O.S. Tan, Problem Based Learning And Creativity, National Institute of Education, Nanyang Technological University, Singapore, 2009.

[4] Joyce, B. Weil, Marsha \& Calhoun E. 2009. Models Of Teching Yogyakarta: Pustaka Pelajar

[5] Rusman. 2013.Learning Models. Jakarta: PT Raja Grafindo Persada

[6] R.A. Sani . 2017. Scientific learning for the implementation of the 2013 curriculum. Jakarta: PT. Bumi Aksara.

[7] Trianto., 2009, Designing Innovative-Progressive Learning Models, Penerbit Kencana, Jakarta. 